\title{
Scaling wave impact pressures on vertical walls
}

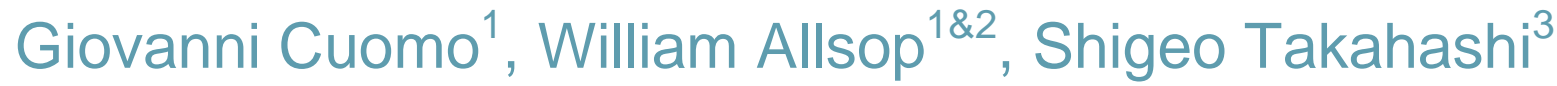

${ }^{1}$ Senior Engineer, Engineering Hydraulics \& Structures Group. HR Wallingford, Howbery Park, Wallingford, OX10 8BA, UK;

JSPS Post-Doc Research Fellow at Maritime Structures Division, Marine Environment and Engineering Department (PARI); Fax: +44 (0)1491 832233, Email address: g.cuomo@hrwallingford.co.uk

${ }^{2}$ Technical Director, Engineering Hydraulics \& Structures Group. HR Wallingford, Howbery Park, Wallingford, OX10 8BA, UK;

Visiting Professor, Department of Civil and Environmental Engineering, University of Southampton, UK. E-mail address: w.allsop@hrwallingford.co.uk

${ }^{3}$ Executive Researcher and Director of Tsunami Research Center, Port and Airport Research Institute, 3-1-1, Nagase, Yokosuka, Japan 239-0826, Fax :

+81-46-844-1274; E-mail address: takahashi_s@pari.go.jp.

Published in Coastal Engineering, 57 (4), (2010)

\section{Abstract}

It is widely recognized that use of Froude similarity for scaling up wave impact pressures recorded during physical model tests may lead to over-estimation of impact maxima. Based on review of historical work dating back to 30's and further developments in the 60's and 80's., a general method is presented that is suitable for scaling up impact pressures and rise times measured during small scale physical model tests. The method accounts for the effect of air leakage and is applicable to wave impact loads on different coastal structures. The model is applied to scale up wave impact pressures on vertical walls and consistent correction factors for Froude scaling law are derived.

This is the author's version of a work that was accepted for publication in Coastal Engineering. Changes resulting from the publishing process, such as peer review, editing, corrections, structural formatting, and other quality control mechanisms may not be reflected in this document. Change may have been made to this work since it was submitted for publication. A definitive version was subsequently published in Coastal Engineering Volume 57, Issue 6, June 2010. DOI: 10.1016/j.coastaleng.2010.01.004.

\section{Keywords}

Scale effects, Scaling law; Wave impacts; Compression law, Physical models

\section{Introduction}

\section{The problem}

Wave loads on vertical breakwaters or seawalls may conveniently be divided between slowly acting loads, having durations between approximately 0.2 and 0.5 of a wave period, generally termed "pulsating" or "quasi-static" loads; or short duration high intensity loads termed "impulsive" or "impact" loads, often having durations closer to $1 / 100$ of the mean wave period $\left(T_{m}\right)$ or shorter, see Figure 1. Generic research under European projects MCS and PROVERBS, see Oumeraci et al (2001) and various national projects (e.g. VOWS in the UK, Cuomo et al. 2009) has led to much greater clarity on prediction, derivation and use of these different load types. As there are very few records of these wave loads from field measurements, 
prediction methods are almost exclusively based on measurements of wave loads at small scale, see e.g. McKenna (1997), Allsop et al (1996), Goda (2000), Cuomo (2005).
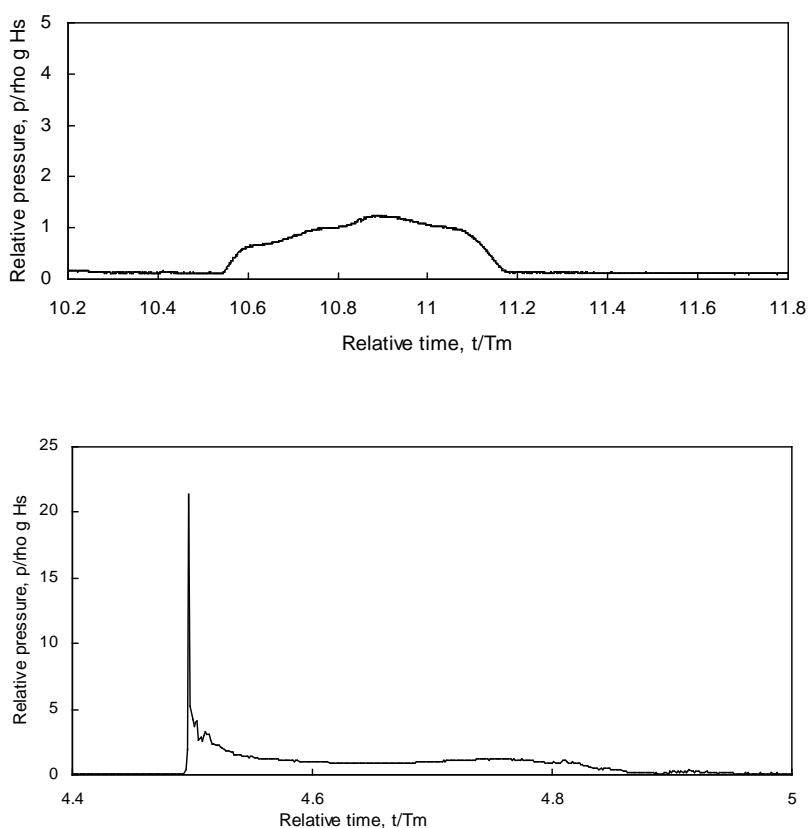

Fig 1: Pulsating (top) and impulsive (bottom) wave pressures, after McKenna (1997) and Allsop et al (1996).

It is well accepted that "pulsating" or "quasi-static" loads can be scaled by simple Froude relationships without any need for adjustment (scale correction). In contrast, it is generally agreed that the magnitudes and durations of "impulsive" wave loads may be strongly influenced by air effects in ways that cannot be scaled by Froude. This leaves the user of wave load data from hydraulic model tests with significant uncertainties, especially in the use of high intensity impulsive loads. Bearing this in mind, in the following a method is presented that is suitable for scaling up impact pressures and rise times measured during small scale physical model tests.

\section{Previous advice on scale corrections}

Many scientific reviews (see among others Bullock et al., 2001) have discussed these problems and have highlighted approaches using scaling based on Cauchy, Weber and others laws, but none have generated practical scale correction methods. Some practical advice on adjusting the scaling of impulsive wave loads has however been developed based on field measurements (3270 impact events) by Allsop et al (1995) compared with laboratory tests of 632 impacts by Howarth et al (1996) at 1:32 scale. Impact pressures measured at small scale in fresh water were compared with pressures measured in the field in seawater. Impact pressures $\left(p_{\max }\right)$ and rise times $\left(t_{r}\right)$ were used to calculate pressure impulse, $\mathrm{I}=p_{\max } \cdot t_{r}$, which showed close agreement over non-exceedance levels 92-99.9\%, supporting the thesis that pressure impulse could indeed be scaled by Froude, even where pressures or rise times cannot. 
Allsop et al (1996) compared impact pressures to suggest a simple relationship between field and laboratory pressures over non-exceedance levels of 92 - 99\%, implying that impact pressures measured at small scale in fresh water should be corrected by factors between about 0.40 to 0.45 after Froude scaling. For rise times (and durations) a similar approach was taken with correction factors summarised in Table 1.

Table 1: scaling factors for pressure impact maxima ( $\left.p_{\max }\right)$ and rise times $\left(t_{r}\right)$, after Allsop et al. (1996)

\begin{tabular}{|l|c|c|}
\hline $\begin{array}{l}\text { Non- } \\
\text { exceedance } \\
\text { level }\end{array}$ & \multicolumn{2}{|c|}{ Correction factors } \\
\hline & $p_{\max }$ & $t_{r}$ \\
\hline $95 \%$ & $\mathbf{0 . 4 5}$ & $\mathbf{7}$ \\
\hline $99 \%$ & $\mathbf{0 . 4 0}$ & $\mathbf{4}$ \\
\hline
\end{tabular}

This approach has the major advantage of simplicity in use, but suffers from significant limitations in not including any effects of scale ratio, impact type, influence of wave conditions and/or water depth etc. This note therefore develops a more complete approach based on historical work going back to 1939.

\section{The Bagnold-Mitsuyasu Compression Law}

Bagnold (1939) first highlighted the similitude between compression of air trapped between water waves impinging on a vertical wall to that of a water hammer compressing air in a piston (Figure 2).
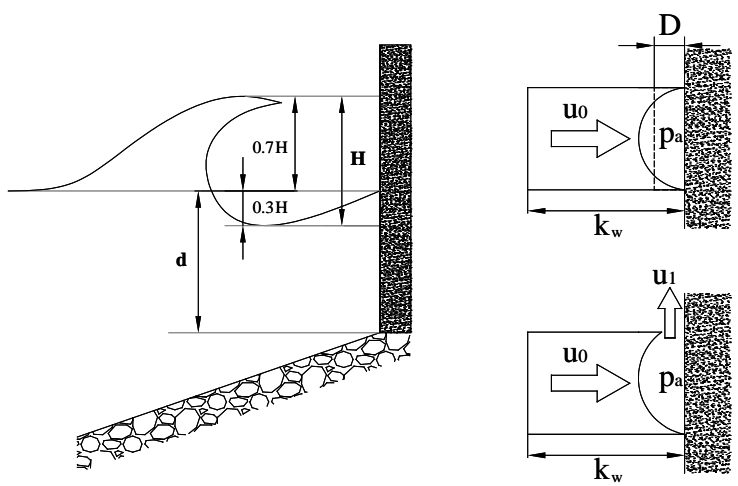

Fig 2: Problem definition sketch. 
The motion of the water mass obeys the following:

$$
\rho_{w} \cdot k_{w} \frac{d^{2} x(t)}{d t^{2}}=p(t)-p_{0}
$$

In which $\rho_{w}$ is the water density, $p(t)$ is pressure in air, $p_{0}$ is the reference (atmospheric) pressure, $x(t)$ is the distance between the wave front (air/water interface) and the vertical wall and $k_{w}$ is thickness of the water mass effectively contributing to the impact.

Assuming air to compress adiabatically within the chamber, and in the absence of air leakage, the following expression is valid between $p(t)$ and $x(t)$ in Equation 1:

$$
p(t)=p_{0} \cdot\left[\frac{D}{x}\right]^{\gamma}
$$

In which $D$ is the thickness of the air layer in the compression chamber and $\gamma=1.4$ is the ratio of the air specific heat at constant pressure to that at constant volume.

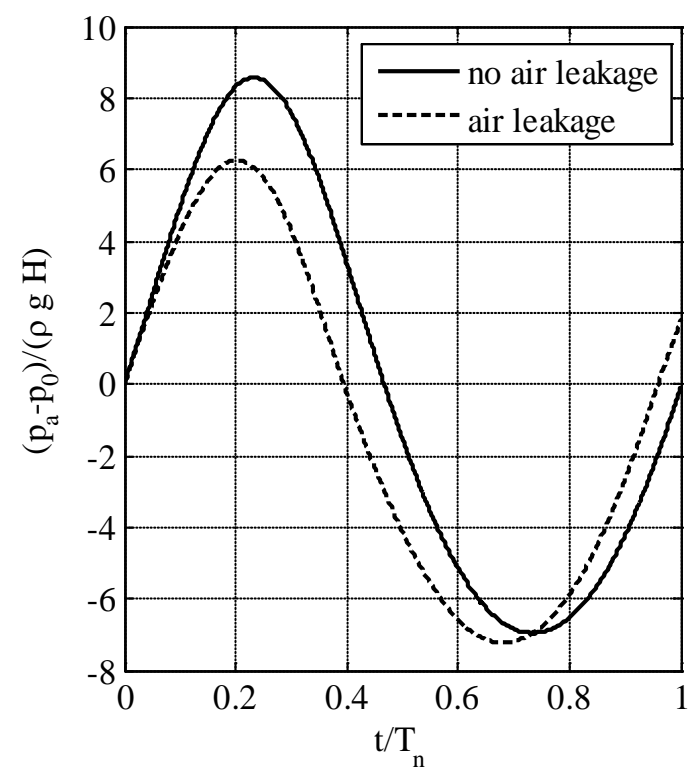

Fig 3: Example calculation of (idealised) pressure time-history, without (solid line, Eq. 2) and with (dashed line, Eq. 6) air leakage. 


\section{Peak pressure}

Equations 1 and 2 can be solved numerically to give variation of $p(t)$ in time, given the initial conditions at $t=t_{0}$

$$
\begin{aligned}
& x=D \\
& \frac{d x}{d t}=-u_{0}
\end{aligned}
$$

Where $u_{0}$ the velocity of the water hammer, which in this case correspond to the wave crest celerity.

Example pressure time-history using Equations 1 and 2 are given in Figure 3, time is normalized with respect to the period of oscillation of the air pocket in the chamber, given by:

$$
T_{n}=2 \pi \sqrt{\frac{\rho_{w} k_{w} D}{\gamma p_{0}}}
$$

\section{Air leakage}

To justify damping of pressure time-histories observed during physical model tests, Mitsuyasu (1966) and Lundgreen (1969) extended the original work by Bagnold to account for damping due to energy losses by air leakage at impacts. Takahashi et al. (1985) have analysed the problem of impulsive uplift pressure to the ceiling slab of a slit-wall caisson seawall having air relieve holes and applied their approach to the problem of scaling impulsive breaking wave pressure. Following derivation by Takahashi et al (1985) Equation 2 can be modified as follows:

$$
p(t)=p_{0} \cdot\left[\frac{D-q(t)}{x}\right]^{\gamma}
$$

In which $q(t)$ is the amount of air that leaks out of the chamber (Takahashi et al. 1985) or out of the air pocket with velocity $u_{1}$ (Figure 2 ) which, assuming that the velocity of leaking air is proportional to relative pressure $p-p_{0}$, can be expressed as:

$$
q(t)=\varepsilon \cdot C_{a} \cdot C_{v} \cdot \int_{0}^{t} \sqrt{2 \rho_{a} \cdot\left(p-p_{0}\right)} d t
$$

where $\rho_{a}$ is the density of air, $\varepsilon$ is the equivalent opening ratio available for air leakage and $C_{a}$ and $C_{v}$ are respectively the contraction and the velocity factors for the air flow through the openings. 


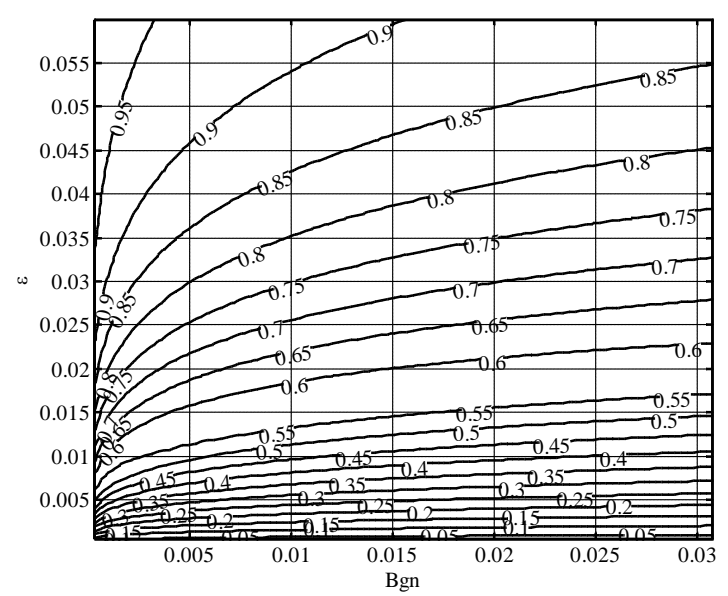

Fig 4: Reduction of peak pressure due to air leakage at impact, as a function of the Bagnold number (Bgn) and the opening ratio $(\varepsilon)$.

Effect of air leakage on pressure time-history by means of damping due to air leakage is represented in Figure 3 , showing variation of pressure in time with $(\varepsilon>0)$ and without $(\varepsilon=0)$ leakage and $C_{a} \cdot C_{v}=0.66$ (Takahashi et al., 1985).

Reduction in peak pressure due to air leakage is further illustrated in Figure 4, showing the ratio of the peak pressure with air leakage to the pressure without leakage as a function of the opening ratio $\varepsilon$ and Bagnold number (Bgn ) defined as (Takahashi et al., 1985):

$$
\operatorname{Bgn}=\frac{\rho_{w} \cdot k_{w} \cdot u_{0}^{2}}{p_{0} \cdot D}
$$

as a function of $k_{w}, D, u_{0}$ and $p_{0}$; the product $C_{a} \cdot C_{v}$ was kept constant in the calculations and equal to 0.66 .

\section{Scale effects}

In absence of air leakage, the following relation exists (Takahashi et al., 1985):

$$
\text { Bgn }=5 \cdot\left(\frac{p_{\max }}{p_{0}}\right)^{2 / 7}+2 \cdot\left(\frac{p_{\max }}{p_{0}}\right)^{-5 / 7}-7(9)
$$

between $\mathrm{Bgn}$ and the relative (to atmospheric) maximum pressure $p_{\max } / p_{0}$. 
From Equations 8 and 9 it follows that $p_{\max } / p_{0}$ (and thus impact pressure) depends on the Bagnold number. Since the reference (atmospheric) pressure $p_{0}$ cannot be scaled in the model, measurements at model scale need to be corrected by a factor $\lambda_{s}$ given by:

$\lambda_{\mathrm{s}}=\frac{\left(p_{\max , P}-p_{0}\right) / p_{0}}{\left(p_{\max , M}-p_{0}\right) / p_{0}}$

where $p_{\max , M}$ and $p_{\max , P}$ are respectively the maximum peak pressures at model (as measured) and prototype scale (to be predicted).
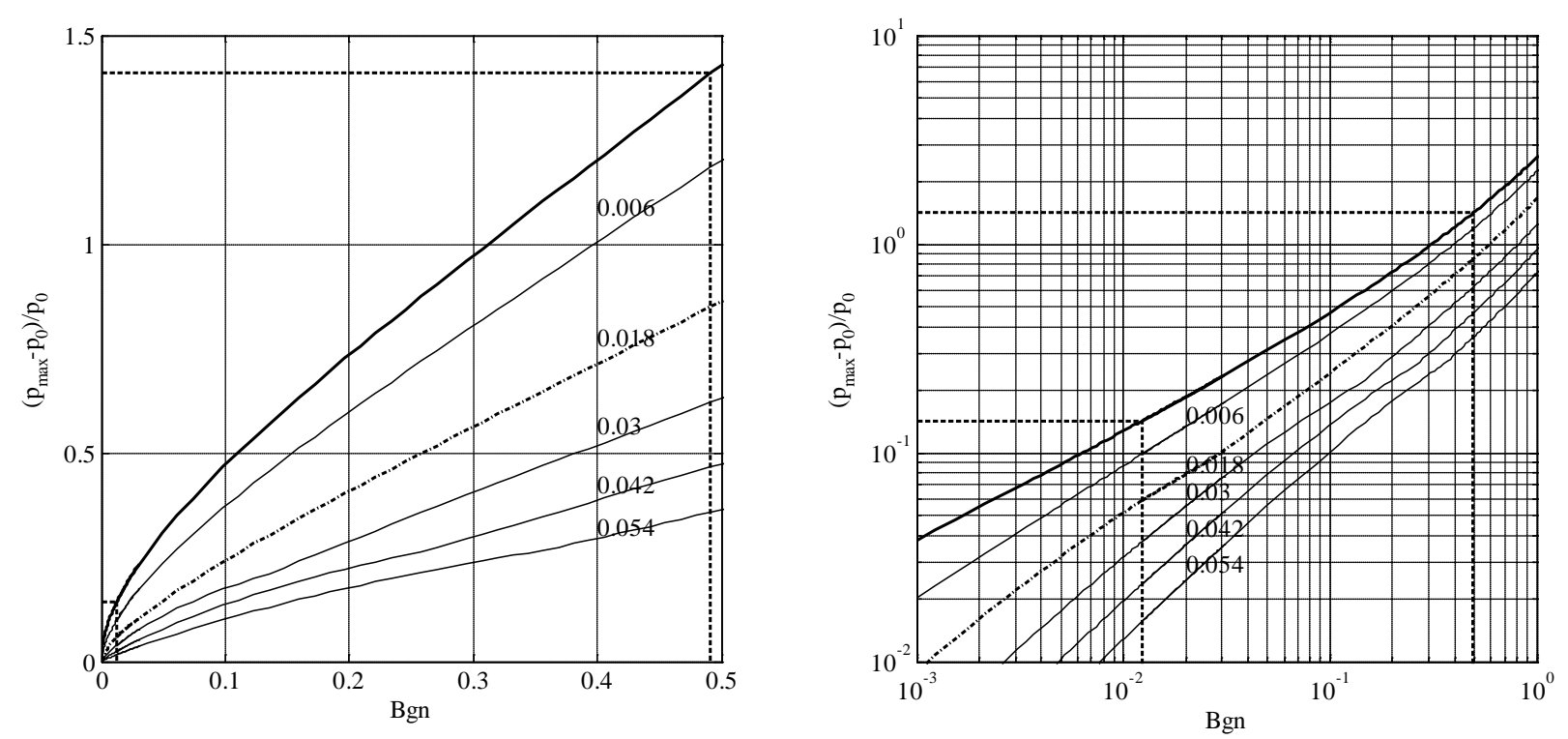

Fig 5: Analytical solution of Equation 9 (left: linear scale, right: log scale), assuming no air leakage $(\varepsilon=0$, bold line) and different degrees of air leakage $(\varepsilon>0$, thin line).

\section{Corrections for scale effects}

To scale pressure $\mathrm{P}_{\mathrm{M}}$ at model scale to pressure $\mathrm{P}_{\mathrm{P}}$ at prototype scale, the following procedure is suggested:

1. evaluate (at both model and prototype scale) parameters $u_{0}, D$ and $k_{w}$ as a function of the geometrical characteristics of the problem (see next section);

2. evaluate Bagnold number at model $\left(B g n_{M}\right)$ and prototype $\left(B g n_{P}\right)$ scale using Equation 8 ;

3. solve Equation 9 for $p_{\max , M}$ and $p_{\max , P}$;

4. evaluate scaling factor $\lambda_{s}$ using Equation 10 . 


\section{Application to scaling wave impact pressures on walls}

Parameters $u_{0}, D$ and $k_{w}$ that appear in the expression of the Bagnold number depend on the geometrical characteristics of the flow at impact. For breaking waves impacting a vertical wall, the following assumptions are suggested (see definition sketch in Figure 2) and are used in the following example calculations:

- the characteristic wave crest velocity $u_{0}$ is taken as that of the solitary wave having height equal to the significant (spectral) wave height $H_{m 0}$ and propagating over a constant water depth $d$, that is (Munk, 1949):

$u_{0}=\sqrt{g\left(d+H_{m 0}\right)}$

- $D$ is taken as the characteristic linear dimension of the (assumed) circular air pocket having area $A$ and radius $R=H_{m 0} / 6$, that is (Figure 2):

$D=\pi / 12 \cdot H_{m 0}$

- based on observations in Bagnold (1939) and Mitsuyasu (1966), $k_{w}$ is taken as (Figure 2):

$k_{w}=0.2 \cdot(1-\pi / 12) H_{m 0}$

For breaking-wave impact pressures on walls with no air leakage, the scaling factor $\lambda_{s}$ has been evaluated using the procedure described above for different combinations of Bagnold numbers at model and prototype scale. Results are given in Figure 6 in terms of Froude scaling factor (left) and corresponding correction factors to Froude scaling (right).
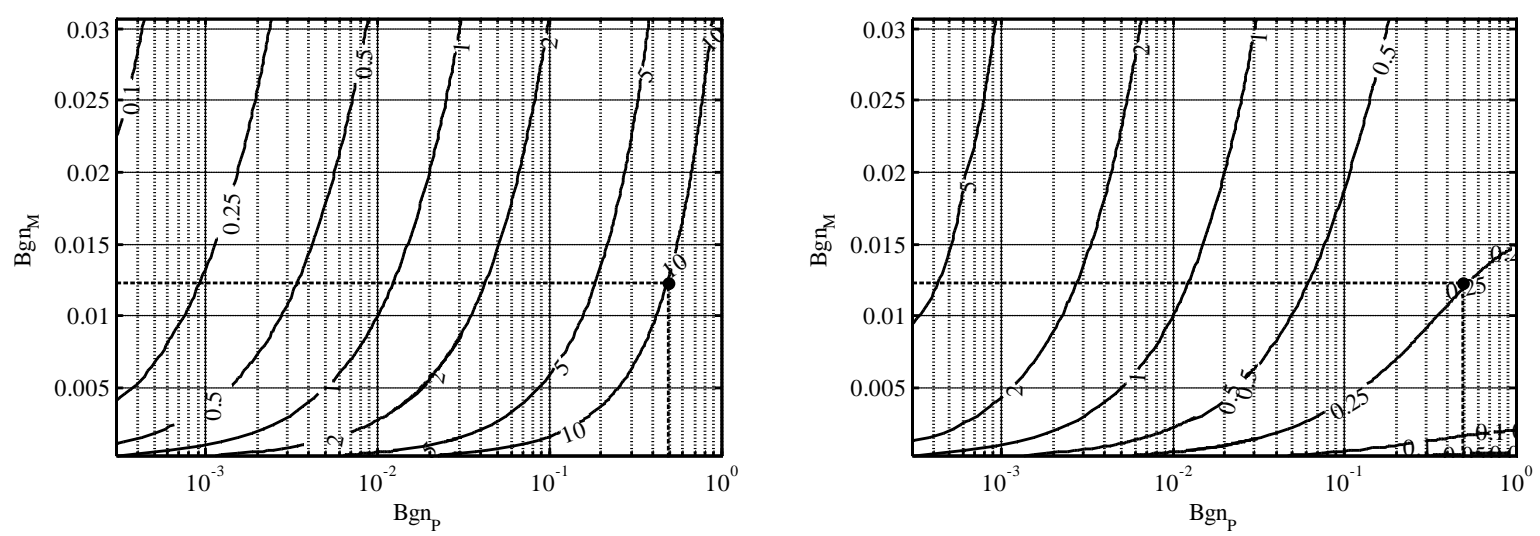

Fig 6: Scale factors (left) and correction factors to Froude (right) for the no-air leakage case $(\varepsilon=0)$ as a function of the Bagnold number at model and prototype scale. 
Figure 6 may be used as follows:

1. Evaluate the Bagnold number at model $\left(B g n_{M}\right)$ and prototype scale $\left(B g n_{P}\right)$ using Equation 8.

2. The scaling factor can be read in Figure 6 at interception of the horizontal line for $B g n=B g n_{M}$ and the vertical for $B g n_{=} \mathrm{Bgn}_{P}$.

\section{Example application}

Let the model scale be 1:40, design significant wave height to be $H_{m 0}=0.10 \mathrm{~m}$ and the water depth at the wall $d=H_{m 0} / 0.8$ (incipient breaking). The corresponding Bagnold number (at model scale) is (Equation 8) $\mathrm{Bgn}_{M}=0.012$. The maximum impact pressure (relative to atmospheric) expected to occur during tests is: $\left(p_{\max , M}-p_{0}\right) / p_{0}=0.14$.

At prototype scale, we have $H_{m 0}=4.0 \mathrm{~m}$ and $d=5.0 \mathrm{~m}$, using Equations $11-13$ leads to:

- $u_{0}=9.4 \mathrm{~m} / \mathrm{s}$

- $D=1.05 \mathrm{~m}$

- $k_{w}=0.6 \mathrm{~m}$

The corresponding Bagnold number (at prototype scale) is $\mathrm{Bgn}_{P}=0.49$.

Entering (Equation 8) with $\mathrm{Bgn}_{P}$ leads to $\left(p_{\max , P}-p_{0}\right) / p_{0}=1.4$.

Based on values of prototype and model relative pressures above, the scale factor $\lambda_{s}$ is equal to 10 and thus the prototype relative pressure is only 10 times larger than in the model, that is, no more than 0.25 times that predicted using Froude scaling law.

This is confirmed in Figures 5 and 6, with dashed lines corresponding to incident wave conditions at model and prototype scales as summarized in Table 2 .

\section{Effect of air leakage}

Note that $\mathrm{Bgn}_{M}$ evaluated according to Equation 8 might be different from that predicted by entering Equation 8 with the maximum peak pressure recorded at model scale. This might be due to a series of causes including air leakage at impact and air entrainment in water. In what that follow we will assume that these damping effects are well represented by mean of an "equivalent" energy loss due to air leakage.

Bearing this in mind, we can now get a better estimate of the scale correction factor, estimating the opening ratio $\varepsilon$ which in our simplified model produces the same amount of energy losses observed in the model. To do this we next enter the plot in Figure 5 and identify the curve passing through point of interception between $\left(p_{\max , M}-p_{0}\right) / p_{0}$ and $B g n_{M}$. Let the maximum impact pressure actually recorded during tests to be 
$\left(p_{\max , M}-p_{0}\right) / p_{0}=0.06$, for $\mathrm{Bgn}=\mathrm{Bgn}_{M}=0.012$, the equivalent opening ratio is $\varepsilon=0.018$ (Figure 5). We can now adjust the scaling factor to account for air leakage, following the procedure described above, but moving along the corresponding (dash-dotted) curve in Figure 5.

The corrected value of $\left(p_{\max , P}-p_{0}\right) / p_{0}$ is 0.85 , and thus $\lambda_{s}=14$ (Figure 7 , left), that is 0.35 times that obtained using Froude scaling (Figure 7, right).

Table 2: Summary of parameters used in the example calculation, at model and prototype scale.

\begin{tabular}{|l|c|c|c|}
\hline & Unit & Model & Prototype \\
\hline$H_{m 0}$ & $\mathrm{~m}$ & 0.10 & 4 \\
\hline$T_{m}$ & $\mathrm{~s}$ & 1.5 & 9.5 \\
\hline$d$ & $\mathrm{~m}$ & 0.125 & 5. \\
\hline$u_{0}$ & $\mathrm{~m} / \mathrm{s}$ & 1.5 & 9.4 \\
\hline$k_{w}$ & $\mathrm{~m}$ & 0.015 & 0.6 \\
\hline$D$ & $\mathrm{~m}$ & 0.03 & 1.05 \\
\hline Bgn & - & 1.2 & 0.49 \\
\hline$\left(p_{\max , M}-p_{0}\right) / p_{0}$ & - & 0.14 & 1.4 \\
\hline
\end{tabular}
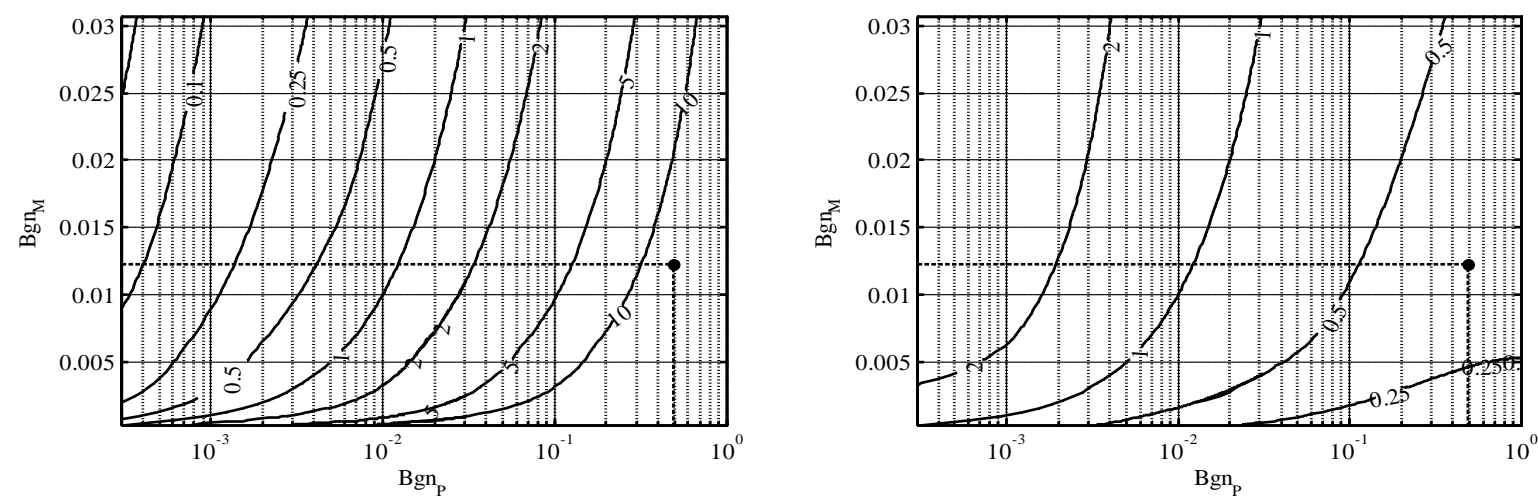

Fig 7: Scale factors (left) and correction factors to Froude (right) for $\varepsilon=0.018$ as a function of the Bagnold number at model and prototype scale. 


\section{Further considerations}

Using the procedure described above, the scaling factor $\lambda_{s}$ can be evaluated for breaking-wave impact pressures on walls for any value of the opening ration $\varepsilon$. Effect of air on scaling can be accounted for as follows:

1. Evaluate the opening ratio $\varepsilon$ that best matches observation during testing, by identifying the curve in Figure 5 that crosses points of interception between maximum pressure recorded in the model and $\mathrm{Bgn}_{M}$.

2. Use the above procedure to derive ad-hoc normogram corresponding to $\varepsilon$ in point 1 above. Example normogram corresponding to $\varepsilon=0.018$ is shown in Figure 7 .

3. The scaling factor can be read in Figure 7 (or equivalent, for the more appropriate value of $\varepsilon$ ) at interception of the horizontal line for $B g n=B g n_{M}$ and the vertical line for $B g n=B g n_{P}$.

\section{Scaling impact rise times}

Once the scaling factor for $p_{\max , P}$ has been calculated, the corresponding rise times $t_{r, P}$ can be immediately derived based on the conservation of pressure impulse, leading to:

$t_{r, P}=\frac{\lambda_{F}^{3 / 2}}{\lambda_{s}} t_{r, M}$

where $\lambda_{F}$ is the Froude scale.

\section{Conclusions and recommendations}

Based on review of historical work dating back to 30's and mainly on work by Takahashi et al. (1985), a method has been presented that is suitable for scaling up impact pressures measured during small scale physical model tests. The method accounts for the effect of air leakage and is applicable to wave impact loads on different coastal structures.

Example application of the proposed methodology to the case of wave impacts on seawalls or caisson breakwaters have been illustrated and normograms derived for scale factors for use in scaling impact pressures from model to prototype.

This study confirms that use of Froude scaling law might lead to significant overestimation of impact pressures at prototype scale. Correction factors for Froude scaling law have also been derived.

When (little) air leakage occur at impact, the relative importance of scale effects might reduce. In such cases, not accounting for air leakage might lead to underestimation of effective scale factor.

As a rule of thumb, when little or no information is available on the level of aeration at impact, users are advised that safer estimates of scaling and correction factors can be obtained using: 
- the lowest value of $\mathrm{Bgn}_{M}$ (among those observed in the model);

ne largest value of $\mathrm{Bgn}_{P}$ (among those expected at prototype scale);

n the largest value of $\varepsilon$ observed during testing.

\section{Further work}

The proposed methodology consistently accounts for the effects of scale ratio, impact dynamics, air compression and leakage and is in agreement with results from previous researchers. Nevertheless, it should be kept in mind that the understanding of the effective role of air compression, entrapment, entrainment and leakage on the dynamics of wave impacts on coastal structures still hands to our community some of its most fascinating question marks. Further and ongoing research work include comparison of data from small scale physical model tests with full scale and field measurements, but also numerical simulations of compressible fluids flows at different scales and development of analytical solutions to account for the effect of compressibility of air and water mixture at impact.

\section{Acknowledgements}

Support from HR Wallingford is gratefully acknowledged. The first author had the opportunity to join the Port and Airport Research Institute under the JSPS post-doc program supported by the Japanese Society for the Promotion of Science.

\section{Notation}

d water depth $\quad[\mathrm{m}]$

$k_{w} \quad$ thickness of the water mass effectively contributing to the impact. $\quad[\mathrm{m}]$

$p(t) \quad$ pressure $\quad[\mathrm{Pa}]$

$\begin{array}{lll}p_{0} & \text { reference (atmospheric) pressure } & {[\mathrm{Pa}]}\end{array}$

$p_{\max } \quad$ peak pressure $\quad[\mathrm{Pa}]$

$q(t) \quad$ amount of air that leaves the chamber trough openings $\quad\left[\mathrm{m}^{3} / \mathrm{s}\right]$

$u_{0} \quad$ velocity of the water hammer $\quad[\mathrm{m} / \mathrm{s}]$

$x(t) \quad$ position of the air/water interface $\quad[\mathrm{m}]$

$\begin{array}{lll}\text { Bgn } & \text { Bagnold number }\end{array}$

$\mathrm{Bgn}_{M} \quad$ Bagnold number at model scale

$\mathrm{Bgn}_{P} \quad$ Bagnold number at prototype scale [-]

$C_{a} \quad$ contraction factor $\quad[-]$ 


$\begin{array}{lll}C_{v} & \text { velocity factor } & {[-]} \\ D & \begin{array}{l}\text { thickness of the air layer in the compression chamber / } \\ \text { characteristic linear dimension of the air pocket }\end{array} & {[\mathrm{m}]} \\ H_{m 0} & \text { significant (spectral) wave height } & {[\mathrm{m}]} \\ I & \text { pressure impulse } & {[\mathrm{Pa} \mathrm{s}]} \\ T_{m} & \text { mean wave period } & {[\mathrm{s}]} \\ T_{n} & \text { period of oscillation of the air pocket } & {[\mathrm{s}]} \\ \gamma & \text { polytrophic index for air }=1.4 & {[-]} \\ \varepsilon & \text { opening ratio } & {[-]} \\ \rho_{a} & \text { air density } & {\left[\mathrm{kg} / \mathrm{m}^{3}\right]} \\ \rho_{w} & \text { water density } & {\left[\mathrm{kg} / \mathrm{m}^{3}\right]} \\ \lambda_{F} & \text { Froude scale factor } & {[-]} \\ \lambda_{s} & \text { scale correction factor } & {[-]}\end{array}$

\section{References}

Allsop N.W.H., Vann A.M., Howarth M., Jones R.J. \& Davis J.P. (1995) "Measurements of wave impacts at full scale: results of fieldwork on concrete armour units" pp287-302, ICE Conf. on Coastal Structures and Breakwaters '95, Thomas Telford, London.

Allsop N.W.H., McKenna J.E., Vicinanza D. \& Whittaker T.J.T. (1996) "New design formulae for wave loadings on vertical breakwaters and seawalls" $25^{\text {th }}$ ICCE, September 1996, Orlando, publn. ASCE, New York.

Bagnold R.A. (1939) "Interim report on wave pressure research", J. Inst. Civil Eng. 12, 202-226, ICE, London Bullock, G. N., Crawford, A. R., Hewson, P. J., Walkden, M. J. A. and Bird. P.A.D. (2001) "The influence of air and scale on wave impact pressures" Coast. Eng. 42:291-312.

Cuomo, G. (2005) "Dynamics of wave-induced loads and their effects on coastal structures" PhD thesis, Science of Civil Engineering, University of Roma Tre, Italy.

Cuomo G., Allsop N.W.H., Bruce T.B. \& Pearson, J. (2009) "Impulsive wave loads at vertical sea walls \& breakwaters" Accepted for publication in Coastal Engineering.

Goda Y. (2000) "Random Seas and Design of Maritime Structures", World Scientific, Singapore

Howarth, M. W., Allsop, N. W. H. , Vann, A. M., Davis, J. P. and Jones., R. J. (1996) "Scale effects of wave impact pressures on cob armour units" Proc. $25^{\text {th }}$ ICCE, Orlando, Florida, USA. ASCE New York, 2522-2531.

Lundgren H. (1969) "Wave shock forces: an analysis of deformations and forces in the wave and in the foundation" Proc. Symp. on research in wave action. Delft Hydraulics Lab. Delft, the Netherlands. 
McKenna J.E. (1997) "Wave forces on caissons and breakwater crown walls" Ph.D thesis, Queen's University of Belfast, September 1997, Belfast.

Mitsuyasu H. (1966) "Shock pressure of breaking waves" Proc. of $10^{\text {th }}$ Int. Conf. Coastal Eng., Tokyo, Japan. ASCE New York, 268-283.

Munk W. H. (1949) "The solitary wave theory and its application to surf problems" Annals of the New York Academy of Sciences 51 (3), 376-424.

Oumeraci, H.; Kortenhaus, A.; Allsop, N.W.H.; De Groot, M.B.; Crouch, R.S.; Vrijling, J.K.; Voortman, H.G. (2000) Probabilistic Design Tools for Vertical Breakwaters. 373 pp, ISBN 905809248 8, publn. Balkema, Rotterdam.

Takahashi S., Tanimoto K. and Miyanaga S. (1985) "Uplift wave forces due to compression of enclosed air layer and their similitude low" Coast. Eng. In Japan, Vol. 28, 191-2 